\title{
Violencia política y domesticación de la experiencia traumática en el cuento "En el vientre de la noche", de José de Piérola
}

Political violence and domestication of the traumatic experience in the story "En el vientre de la noche", by José de Piérola

\author{
Miguel Ruiz Effio \\ Universidad Nacional Mayor de San Marcos, Lima, Perú \\ Contacto:miguel.ruiz@unmsm.edu.pe \\ http://orcid.org/0000-0003-3812-9996
}

\begin{abstract}
Resumen
La violencia política constituye una de las manifestaciones contemporáneas de la violencia urbana. En el Perú, el período del conflicto armado interno (1980-2000) representa una experiencia traumática que ha encontrado en la literatura realista un vehículo oportuno para dar testimonio de esta problemática. El presente trabajo analiza el cuento "En el vientre de la noche", del escritor peruano José de Piérola (Lima, 1961), con el objetivo de identificar los mecanismos de representación de la violencia política y sus marcas en el texto, tanto en el argumento como en los elementos retóricos del discurso.
\end{abstract}

Palabras clave: Narrativa; Cuentos; Literatura realista; Violencia política; José de Piérola.

\begin{abstract}
Political violence constitutes one of the contemporary manifestations of urban violence. In Peru, the period of the internal armed conflict (1980-2000) represents a traumatic experience that has found in the realistic literature an opportune vehicle to testify to this problem. The present work analyzes the story "En el vientre de la noche", by the Peruvian writer José de Piérola (Lima, 1961), with the aim of identifying the mechanisms of representation of political violence and its marks in the text, both in the argument as in the rhetorical elements of speech.
\end{abstract}

Keywords: Narrative; Stories; Realistic literature; Political violence; José de Piérola.

Recibido: 18.02 .20

Aceptado: 06.06.20 


\section{Introducción}

Los primeros años del siglo XXI concedieron al Perú un período de estabilidad económica. Ello se tradujo en la disminución de los índices de pobreza, el resurgimiento de una clase media renovada y la modernización de las ciudades del país, esto último gracias a la globalización, la comunicación digital y el auge de las redes sociales. Tales nuevos factores, entre muchos otros, originaron inéditas maneras de interactuar, lo que se refleja, a su vez, en desconocidos tipos de violencia que se muestran con mayor grado e impacto en las ciudades contemporáneas.

La violencia urbana es una resultante de renovadas tensiones y aspiraciones de los grupos humanos que pueblan los países, pues el progreso origina, también, exclusión y acceso desigual a los sistemas de convivencia (Moser \& Mcllwaine, 2009, p. 13). En el caso peruano, el largo y doloroso conflicto armado interno (1980-2000) sacudió al país durante dos décadas y dejó huellas en la idiosincrasia de los ciudadanos, quienes interiorizaron la violencia como un recurso para enfrentar los conflictos de la vida social (Comisión de Entrega de la CVR, 2008, p. 371).

Carrión (2008) sostiene que la relación entre ciudad y violencia ha sido poco estudiada y aboga por desterrar un antiurbanismo nocivo que establece una correspondencia de causalidad entre ciudad y violencia, pues la violencia sería, más bien, una relación particular dentro del conflicto social. En su análisis, es innegable que existen hechos de violencia típicamente urbanos, originados al interior de una relación ciudad-violencia que progresa en ambas direcciones (pp. 116-123).

Por su parte, Sapiro (2016) afirma que las obras producidas por la literatura devienen en representaciones sociales de su época. A partir de ello, pone énfasis en que la literatura realista, debido a sus pretensiones de reproducir la realidad de un período específico, se presta para ejecutar el ejercicio de leer una época a través de las obras de sus escritores (pp. 79-80). Por ello mismo, Williams (2009) propone que

[...] existen relaciones sociales e históricas evidentes entre las formas

literarias particulares y las sociedades o períodos en que se originaron 
o practicaron; segundo, que existen indudables continuidades de las formas literarias entre —y más allá de— las sociedades y los períodos con que mantienen tales relaciones. (p. 244)

La creación literaria es, por lo tanto, una respuesta del escritor con respecto a una época determinada, sea como testimonio (Sapiro, 2016) o como continuidad del discurso (Williams, 2009). En el primer caso, la violencia originaría un tipo particular de discurso que debería evidenciar las marcas o traumas de aquella (Braunstein, 2012, pp. 81-82). En el segundo caso, las sociedades proporcionan a las literaturas de una época determinada, los motivos y las formas literarias - un conjunto de referentes culturales de diversa índole - que posibilitan la continuidad del discurso, es decir, un repertorio ${ }^{1}$ (Even-Zohar, 2017).

En esta línea de análisis, la violencia urbana en las sociedades contemporáneas halla correlato en la literatura de su época como motivo —una consecuencia natural en la literatura de índole realista - o, también, de un modo más profundo y sutil, "contaminando" los elementos retóricos del discurso. Esto último es una cuestión importante, por cuanto la literatura realista que da cuenta de la violencia urbana, en su condición de testimonio, debe hacerlo a través de un discurso verosímil, para lo cual debería reflejar de alguna manera las marcas de la violencia (Žižek, 2009, p. 12), pues el trauma originado por esta solo puede superarse mediante su domesticación en la memoria o su reelaboración en el discurso (Braunstein, 2012, p. 109).

A partir de estas reflexiones iniciales, desarrollaremos nuestro análisis de "En el vientre de la noche", de José de Piérola (2008), un cuento peruano contemporáneo escrito como representación de la categoría violencia política (Moser \& Mcllwaine, 2009, pp. 16-18) y con una alta inmediatez al contexto histórico al que se refiere.

\section{Las huellas de la violencia}

El 18 de julio de 1992, la incursión de un grupo de agentes del Servicio de Inteligencia del Ejército en la Universidad Nacional Enrique Guzmán y Valle, La Cantuta, terminó con el secuestro y desaparición de nueve alumnos y un profesor. El 3 de julio de 1993, un grupo autodenominado León Dormido reveló un documento que informaba que los desaparecidos habían sido secuestrados, 
asesinados y enterrados en secreto por un escuadrón militar que operaba con autorización de altos mandos del Ejército y del Servicio de Inteligencia Nacional. Meses después, los cuerpos calcinados de varios de ellos fueron hallados enterrados en fosas a las afueras de Lima.

“En el vientre de la noche", de José de Piérola (2008), coge los principales elementos de este suceso como insumo para narrar, de manera pormenorizada, un asesinato extrajudicial que se lleva a cabo durante los años del conflicto armado interno peruano ${ }^{2}$. El oficial Ubilluz recibe la orden de ejecutar a un hombre que ha sido detenido en una vivienda universitaria. Los hechos que ocurren durante la noche del asesinato se narran cronológicamente, en orden lineal, aunque se insertan numerosos flashbacks — podríamos señalar hasta dieciocho- que cumplen la función de revelar al lector varios detalles de la vida familiar de Ubilluz, como su deseo de pasar al retiro por petición de su esposa, con quien acaba de tener un hijo solo ocho meses atrás. En la escena final, Ubilluz se ve obligado a disparar por órdenes del capitán Basurto, su superior, quien le apunta a la sien con un revólver, enfurecido, debido a que hasta ese instante Ubilluz ha retrasado la directriz, luego de haber establecido cierta familiaridad con su víctima y, de alguna manera, porque ha reconocido en él a otro padre de familia con un hijo por quien velar:

- [...] Es una vaina, carajo, la vida es una vaina. Si no fuera por ustedes estaría en mi cama, calientito, con mi mujer.

- Si no fuera por ustedes, Ariel habría tenido su caja de colores.

(De Piérola, 2008, pp. 27-28)

Los flashbacks interrumpen la narración de la noche del asesinato como en una asociación libre que proporciona piezas del pasado sin una cronología rigurosa: se introducen diálogos amorosos de Ubilluz y su esposa y otros de su rutina militar bajo las órdenes del capitán Basurto, pero conforme avanza la historia las escenas se intercalan, se combinan y vuelven complejo el recuerdo, como si la memoria luchara por mantenerlo domesticado (Braunstein, 2012, p. 109). Veamos, en el siguiente extracto, cómo la narración heterodiegética recibe flashbacks de distinto origen (la esposa de Ubilluz y el capitán Basurto), mientras da cuenta del olor de la tierra y del aire de la noche (las cursivas son nuestras): 
La tierra húmeda olía bien. ¿Vamos a venir siempre a Huancayo? Siempre, Negrita, siempre. Ubilluz aspiró profundo sin dejar de apuntar. El aire hasta parecía más puro esa noche. ¿Qué mierda hace, Ubilluz? Nada, mi capitán. ¿Qué se le ha perdido? Nada, mi capitán. Entonces suba a la camioneta, nos vamos. Sí, mi capitán. Mentiroso.

(De Piérola, 2008, pp. 25-26)

El fragmento citado termina con "Mentiroso", voz atribuible a la esposa de Ubilluz. Ella, en una secuencia de siete flashbacks, insiste a su esposo para que pida su baja del Ejército por su seguridad, primero, y, hacia el final del cuento, le reprocha no haber solicitado su pase al retiro a pesar de que ya tienen un hijo de ocho meses por quien preocuparse. La esposa de Ubilluz acusa, por eso: "Mentiroso", mientras que Ubilluz, pareciera tomar la decisión definitiva en las últimas páginas del cuento, tal vez por enfrentarse a la ejecución de su víctima: “Te lo prometo, Negrita, después de esta pido mi baja. [...] No, Negrita, esta vez sí, es la última" (De Piérola, 2008, p. 30).

\section{Violencia política/violencia verbal}

Es evidente que el cuento es una representación de la violencia política, una manifestación de esta que tiene lugar dentro del conflicto armado interno. El cuento toma elementos de un suceso real: la desaparición y asesinato de nueve estudiantes y un profesor de la Universidad Nacional de Educación Enrique Guzmán y Valle, La Cantuta (Comisión de Entrega de la CVR, 2008, pp. 320321), aunque la escena de una ejecución extrajudicial individual corresponde con mayor precisión a los crímenes documentados en la Universidad Nacional del Centro, en Huancayo ${ }^{3}$. En cualquier caso, la naturaleza realista de este cuento extrae su génesis del contexto inmediato y lo reelabora para dar cuenta de una experiencia traumática que el autor hace suya (Braunstein, 2012, pp. 81-82; Tomás Cámara, 2014, p. 208).

Asimismo, es notorio el uso del lenguaje para transmitir varios niveles de violencia a través del discurso indirecto libre. En efecto, como vehículo que da cuenta de la violencia inherente a una ejecución extrajudicial en el contexto de un conflicto armado entre el Estado y un grupo subversivo, el lenguaje hace énfasis en el inquebrantable anonimato del detenido; de este no sabremos nunca el nombre - se le llama "el indio jijuna", al inicio, y luego "el indio con voz de otro" 
en el resto del cuento-. Esta última estrategia alude a la identidad arrebatada a los desaparecidos:

El indio jijuna que caminaba frente a él era sólo una respiración pausada, una silueta sin rostro, un ser sin nombre; uno más. [...] Todos eran medio cholos, medio indios, pelo negro, labios gruesos, pómulos salientes, uno que otro pelo ensortijado. Con la distancia de los meses sería el mismo rostro de indio típico que Ubilluz ya no reconocería aunque se le plantara al frente en carne y hueso con su humanidad acezante y vengadora. (De Piérola, 2008, p. 17)

Calderón (s.f.) ha abordado la cuestión de la actitud ética en el cuento, en tanto representa una comprensión ética de la violencia. Por ello, interpreta que la narración da cuenta de "la asunción de la fantasía racista al servicio de la ideología estatal de la violencia" (Calderón, s.f.), fantasía que se problematiza a medida que el indio revela características que la narración adjudica — siempre a través del discurso indirecto libre, donde se incorpora el pensamiento prejuicioso de Ubilluz y otros personajes - como inherentes a otro tipo de sujeto:

Tanteando con los pies, como si lo hiciera todas las noches, el indio bajó la pendiente sin perder el equilibrio, silencioso, el rostro indefinido en la oscuridad de la noche oscura, la cara de indio, los pómulos salientes, el pelo negro e hirsuto, carajo. Indio ilustrado, Ubilluz, ¿qué le parece? Lo único que nos faltaba, mi capitán. Sí, Ubilluz, pero le vamos a volar la iluminación de un solo cuete. (De Piérola, 2008, p. 18)

Y así como Ubilluz y el capitán Basurto se sorprenden del nivel intelectual del prisionero, el primero lo hace también de su voz, que admira y hace nacer los primeros indicios de solidaridad y complicidad:

— ¿Empiezo a tirar pala? — preguntó el indio con voz tranquila y modulada que pareció venir de una radio. Carajo, indio ilustrado y con voz de otro. Ubilluz hubiera dado cualquier cosa por tener una voz así, en lugar de la voz gangosa que lo hacía quedar tan mal cuando quería palabrear a una mamacita rica. (De Piérola, 2008, p. 19)

Sin embargo, la figura del capitán Basurto es una barrera de violencia — verbal, precisamente - contra la que se estrella cualquier tentativa de entendimiento:

— ¿Casado? — preguntó el indio con voz de otro.

Ubilluz no dijo nada. Jamás hable con un prisionero, a menos que sea 
un interrogatorio, a menos que sea para obtener información, a menos que le haya regalado un buen patadón en los huevos, ¿entiende? Sí, mi capitán. Nunca deje que esos jijunagramputas lo palabreen. (De Piérola, 2008, p. 22)

Esto ocasionará, hacia el final del cuento, que fracase cualquier intento de Ubilluz de no ejecutar la orden y salvar la vida del "indio con voz de otro", quien encarna un reflejo de la vida familiar del protagonista, enfrentado introspectivamente con sus propios valores de solidaridad y compasión.

\section{La reelaboración de la experiencia traumática en el discurso}

En cuanto a los elementos retóricos del cuento introducidos como marcas de la violencia, ya nos hemos referido como una primera característica a la estrategia de referir la violencia impregnada en el discurso del narrador a través del indirecto libre, que diluye o hace ambigua la posición de su enunciador.

En tal sentido, cuando hacia el final del relato la víctima y su victimario dialogan por fin, la narración muestra una desconexión absoluta entre los interlocutores, como si se encontrasen en lugares diferentes o cada quien hablase consigo mismo. Ello hace evidente el fracaso de la comunicación entre sus posturas, a pesar de sus notorios puntos en común (ambos son padres de familia y ambos añoran sus hogares):

- Ariel había dibujado una paloma volando hacia una luna en cuarto menguante, y estrellas, montones de estrellas. Mi mujer me dijo que Ariel las había señalado muy orgullosa.

- Tenemos un hijo, se llama Ernesto.

- Alrededor de las estrellas había dibujado una bola inmensa, llena de rayitas azules - el hombre siguió cavando, la pala siguió enterrándose en la tierra, atravesando guijarros y encontrándose con clavos, pero Ubilluz ya no tuvo escalofríos-. Eso le había dado más cólera a mi suegra.

- Solo tiene ocho meses — Ubilluz movió la cabeza—. En cualquier momento camina el bandido.

-Mi mujer le preguntó que qué era esa bola azul.

- Se llama Ernesto, pero para mí es mi Mochito. (De Piérola, 2008, pp. 26-27)

Otra estrategia a la que recurre el autor es el uso del humor negro, que se dosifica a lo largo del texto para aliviar —o eludir — el dramatismo de la anécdota 
que se describe. Esto es especialmente evidente en dos situaciones donde la narración acoge los pensamientos irónicos de Ubilluz; este contrasta la crueldad de los sucesos con situaciones similares producidas en otro contexto - una espera prolongada, hacer un hoyo en la tierra-, para hacer obvio su desconcierto frente a la tranquilidad del "indio con voz de otro":

Ubilluz se sorprendió. Carajo, ¿por qué mierda hablaba con tanta naturalidad, como si fueran compadres, como si estuvieran preparando una pachamanca? Solo faltaba que le dijera que no había cariño en esa casa, que le pidiera un trago, que le preguntara por la familia.

[...]

El maldito hablaba como si nada, como si estuvieran en la cola del pan, de pantuflas, legañoso, con una bata de felpa amarrada en la cintura. No había miedo en su voz, ni preocupación, ni nada, como si no supiera lo que le iba a pasar.

(De Piérola, 2008, pp. 21, 22)

La incomunicación y la elusión del dramatismo de los hechos narrados a través de la ironía constituyen mecanismos de defensa de la memoria, que domestica un recuerdo traumático por medio de su conversión en anamnesis, en la representación a través de palabras (Braunstein, 2012, p. 109).

\section{Conclusiones}

La violencia urbana muestra características particulares que se originan en las nuevas dinámicas de las urbes contemporáneas. Sus manifestaciones dan lugar a numerosas representaciones en la literatura peruana, puesto que los escritores realistas aspiran a denunciar las problemáticas de su época de manera verosímil. En tal sentido, la violencia política sufrida por el Perú en el período 1980-2000 constituye un evento traumático recogido en la literatura reciente, y que se plasma a través de un discurso que recoge las marcas de la violencia en sus elementos retóricos.

El cuento "En el vientre de la noche", de José de Piérola, toma algunos de los hechos de violencia del período mencionado y los reelabora en un argumento que denuncia los asesinatos extrajudiciales cometidos por las fuerzas del orden peruanas en su intento de enfrentar las acciones terroristas de Sendero Luminoso, aunque se decanta por una mirada introspectiva que cuestiona la ética de tomar una vida humana, en este caso, la del enemigo ideológico. El discurso 
del narrador incorpora también, como marcas de la experiencia traumática de la violencia, el vaivén de la memoria que lucha por zafarse del orden con el que se le ha domesticado, así como una serie de alusiones cargadas de violencia y de ironía que tamizan el dramatismo de los hechos que se narran, con el objetivo de defender la memoria del narrador.

\section{Agradecimientos}

Este artículo es producto de la investigación para la tesis desarrollada con el fin de optar el grado de magíster en Escritura Creativa de la Universidad Nacional Mayor de San Marcos.

\section{Notas}

1 Arámbulo (2016) resume y caracteriza el concepto de repertorio como "una suerte de reglas o parámetros y materiales que regulan la construcción y manipulación (producción y consumo) de un producto dado. [...] Un repertorio es una lista de elección múltiple y de lectura múltiple [...]" (Arámbulo, 2016, p. 46).

2 Sin embargo, la CVR ha establecido que este modus operandi - secuestro y desaparición selectiva - fue utilizado también en la Universidad Nacional del Centro entre 1990 y 1992 (Comisión de Entrega de la CVR, 2008, pp. 264, 266, 320-321). "En el vientre de la noche" obtuvo el XII Premio Internacional de Cuentos 1998 Max Aub, otorgado por la Fundación Max Aub de España, de modo que podríamos rastrear su fecha de composición hasta pocos años después de los hechos de La Cantuta y Huancayo, aun cuando el texto hace una referencia explícita a la sierra de Lima: "Estaban a media hora de Lima; sin embargo, esa cañada abandonada parecía estar en plena puna" (De Piérola, 2008, pp. 18-19). El cuento fue publicado por la editorial Pre-Textos en 2000, ocho años antes de su incorporación al volumen Sur y Norte.

3 La CVR sostiene que el Ejército llevó a cabo "una política de detenciones arbitrarias, tortura, ejecuciones extrajudiciales y desapariciones, de por lo menos 74 personas plenamente identificadas", como respuesta a los crímenes de Sendero Luminoso en su intento de controlar la Universidad Nacional del Centro (Comisión de Entrega de la CVR, 2008, pp. 264, 266).

\section{Referencias bibliográficas}

Arámbulo, C. (2016). Vigencia de la poética de las crónicas del Grupo Narración (Tesis de Licenciatura). Universidad Nacional Mayor de San Marcos, Lima, Perú.

Braunstein, N. (2012). La memoria del uno y la memoria del Otro: inconsciente e historia. Ciudad de México: Siglo XXI Editores. 
Calderón, I. (s.f.). Un indio con voz de otro: el giro ético y sus fisuras en un cuento de José de Piérola [documento de Academia.edu]. Recuperado de: https://www.academia.edu/15310225/_Un_Indio_con_voz_de_otro_el_ giro_ético_y_sus_fisuras_en_un_cuento_de_José_de_Piérola.

Carrión, F. (2008). Violencia urbana: un asunto de ciudad. Eure, XXXIV (103), 111-130. https://doi.org/10.4067/S0250-71612008000300006

Comisión de Entrega de la CVR (2008). Hatun Willakuy. Lima: Comisión de la Verdad y Reconciliación.

De Piérola, J. (2008). Sur y Norte. Lima: Grupo Editorial Norma.

Even-Zohar, I. (2017). Polisistemas de cultura (Un libro electrónico provisorio). Tel Aviv: Universidad de Tel Aviv.

Moser, C. y Mcllwaine, C. (2009). La violencia urbana en Latinoamérica como problema de desarrollo: hacia un marco para reducir la violencia. En A. Lunecke, A. Munizaga y J. Ruiz (Eds.), Violencia y delincuencia en barrios: Sistematización de experiencias (pp. 12-39). Santiago: Fundación Paz Ciudadana y Universidad Alberto Hurtado.

Sapiro, G. (2016). La sociología de la literatura. Buenos Aires: Fondo de Cultura Económica.

Tomás Cámara, D. (2014). Una poética de la violencia. La práctica discursiva en contextos de conflicto extremo en la literatura africana contemporánea (Tesis doctoral). Universidad de Alicante, Alicante, España.

Williams, R. (2009). Marxismo y literatura. Buenos Aires: Las cuarenta.

Žižek, S. (2009). Sobre la violencia. Barcelona: Paidós. 